\title{
The influence of laser line hardening of carbon steel AISI 1045 on the lubricated wear against steel AISI 52100
}

\author{
H. Visscher, M.B. de Rooij, P.H. Vroegop, D.J. Schipper * \\ University of Twente, Faculty of Mechanical Engineering, Tribology Group, P.O. Box 217, 7500 AE Enschede, Netherlands
}

Received 29 April 1994; accepted 20 October 1994

\begin{abstract}
To diminish wear in tribological systems it is not always necessary to provide the entire surface with a wear resistant layer. Depending on the application it is sufficient to harden locally the load carrying areas which are subjected to wear. Such areas can be treated properly by a laser, either totally or partially. This paper describes the effects of laser line hardening on the wear behaviour of carbon steel AISI 1045 against ball bearing steel AISI 52100. It is shown that the wear resistance of carbon steel AISI 1045 can be improved considerably by line hardening the surface. The wear resistance of the laser line hardened surfaces is comparable with that of carburised steel AISI 1045. However, the properties of the laser line hardened areas determine the wear behaviour of the entire system. Furthermore, the experimental work indicates that the type of heat treatment, carried out prior to line hardening in order to improve the microstructure of the steel, has no significant effect on the wear behaviour of the tribological system.
\end{abstract}

Keywords: Laser line hardening; Steel; Surface treatment; Wear behaviour

\section{Introduction}

Laser hardening is a surface treatment by which structural transformations of the material can be established by irradiating the surface with a laser beam. The temperature and hence the properties of the surface can be controlled by the power density and the scan speed (in case of line hardening) or the interaction time (in case of single-shot hardening) of the beam. When the beam exposes the surface the steel will heat up very locally and rapidly to a temperature that will austenise the material. After the beam has passed the material quenches itself and transforms into martensite. The laser hardening method has some specific advantages above conventional hardening methods (such as flame- and induction hardening), and thermochemical treatments (such as carburising, nitriding and carbonitriding). For example, laser hardening permits localised treatment of the workpiece, that is, the energy density and interaction time can be controlled at specific localised places of the material. The characteristics of the laser hardening process make it possible to improve the wear resistance of tribological systems by hardening specific load carrying areas which are subjected to wear.

\footnotetext{
* Corresponding author.
}

In addition, the wear resistance of already existing accurately machined parts, can be improved by laser hardening.

Many comparative studies have been reported on the wear resistance of laser hardened and conventional hardened surfaces [1-6]. However, little attention has been given to the wear resistance of the entire tribological system, the influence of preheat treatments, line pattern, pitch (the distance between the lines), coverage ratio (the line width divided by pitch) and the structure of the lines or hardened patterns on the wear behaviour. Meijer et al. [1] investigated the lubricated wear of a line hardened plate of carbon steel AISI 1045 against a pin made out of ball bearing steel AISI 52100. When the wear resistance of the line hardened plate increased, that of the pin decreased. They distinguished three layers in the cross section of a line: (1) a dendritic grey layer, caused by melting of the surface during laser hardening; (2) a white etching layer, containing retained austenite; (3) a martensitic area. They concluded that the wear resistance of the dendritic layer is inferior to that of the white etching layer. The wear resistance of the martensitic layer was lower than that of the white etching layer. A line pattern parallel to the sliding direction of the pin showed a mixture of both metallic and oxidative wear processes. 
This line pattern consequently gave a higher wear rate of the plate than a line pattern perpendicular to the sliding direction.

In this paper the wear behaviour of laser line hardened carbon steel AISI 1045 against ball bearing steel AISI 52100 is described. The investigation is a continuation of the work of Meijer et al. [1]. The wear results are expressed in specific wear rates, that is, the volume loss per unit of sliding distance per unit of normal load. Although the scattering in the wear rates is large some correlations have been found between coverage ratio, line pattern and microstructure of the hardened areas and the wear behaviour. The wear resistance of laser hardened steel AISI 1045 is compared with that of non-hardened and carburised steel AISI 1045.

\section{Experimental procedure}

The tested tribological system is shown in Fig. 1 and consists of a pin sliding against a plate. The pin is a crowned roller, as used in roller bearings. The dimensions of the elements of the tribological system are given in Table 1. The line patterns are applied to the $58 \times 18 \mathrm{~mm}$ surface of the plate. The plates were line hardened with two types of $\mathrm{CO}_{2}$ lasers operating in continuous mode and with a power of 0.1 and $1.8 \mathrm{~kW}$ respectively.

\subsection{Preconditioning of the samples}

Preliminary to line hardening the plates have been conditioned by different treatments. Table 2 shows the

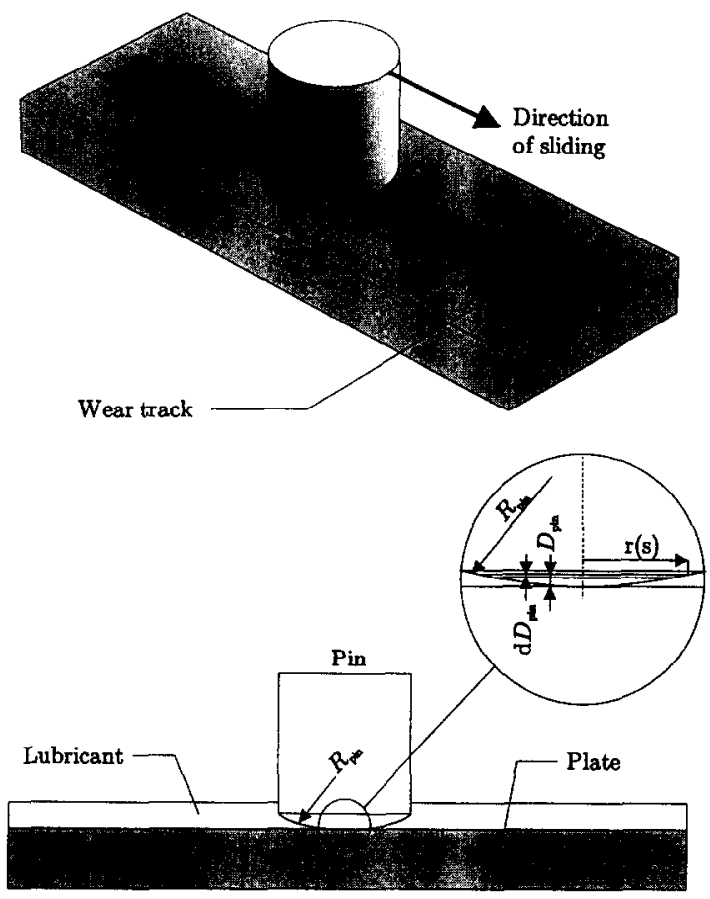

Fig. 1. The tribological system. different groups of plates according to their preconditioning method and laser treatment and Table 3 shows the different preheat treatments. The grinding and polishing treatments resulted in a CLA-roughness of 0.1 and $0.01 \mu \mathrm{m}$ respectively. These treatments were carried out in order to reduce the scattering of the laser light during line hardening. To measure the effect of the roughness refinement on the wear behaviour, some plates were only normalised and ground. In order to study the effects of preheat treatments on the wear behaviour, the plates line hardened by the $1.8 \mathrm{~kW}$ laser have been heat treated by different methods (stress relieving, normalising and quenching + tempering, see Table 3). The objective of the stress relieving treatment is mainly to remove surface residual stresses from the grinding operation. This method has no effect on the microstructure of the steel. The normalising and quenching + tempering treatments give in general a homogeneous martensitic structure after the laser hardening as these treatments result in a refinement in grain size (see for example [1]).

\subsection{Laser line hardening}

The characteristics of the laser line hardened areas depend on the following process variables: power, size and energy distribution of the laser beam, scan speed or interaction time and the composition and microstructure of the steel, which all were varied in this study. The light of the $\mathrm{CO}_{2}$ laser beam (with a relative high wavelength of $10.6 \mu \mathrm{m}$ ) would be strongly reflected by the steel surface (more than $90 \%$ ). To improve the absorptivity of the surface a colloidal graphite coating was applied. The thickness of the coating was 8-10 $\mu \mathrm{m}$. The $0.1 \mathrm{~kW}$ laser beam was active in the $\mathrm{TEM}_{00^{-}}$ mode and the scan speed was $4 \mathrm{~mm} \mathrm{~s}^{-1}$. The $1.8 \mathrm{~kW}$ laser beam was applied with a beam integrator to generate a homogeneous energy distribution in the beam. The scan speed was in this case varied at 3,6 and $12 \mathrm{~mm} \mathrm{~s}^{-1}$. To diminish pre-heating effects, the hardening of each line was started at the same side of the sample, as is shown in Fig. 2. The hardening process is described in detail by Meijer et al. [1]. The interaction time between laser beam and surface was about $0.2 \mathrm{~s}$ for the $0.1 \mathrm{~kW}$ laser beam and $0.5,1.0$ and $2.0 \mathrm{~s}$ for the $1.8 \mathrm{~kW}$ laser beam respectively. These are normal values for laser hardening, see Fig. 3 . The hardening depth and the line width were determined by laser power, scan speed and beam radius.

As a result of differences in specific volume between ferrite, pearlite and martensite, the lines rose 0.1-1.0 $\mu \mathrm{m}$ above the surface (see Figs. 4 and 5). The height and shape of the hardened lines were measured with a stylus profilometer. The Vickers microhardness of the lines has been measured along and perpendicular 
Table 1

Properties of the samples.

\begin{tabular}{llll}
\hline Element & Material & Dimensions/volume $(\mathrm{mm}) /\left(\mathrm{mm}^{3}\right)$ & Vickers hardness/viscosity (GPa)/(Pas) \\
\hline Plate & Line hardened carbon steel AISI & $58 \times 18 \times 5 \mathrm{~mm}$ & $8.0 \mathrm{GPa}$ \\
& 1045 & & \\
& Carburised carbon steel AISI 1045 & $58 \times 18 \times 5 \mathrm{~mm}$ & $8.4 \mathrm{GPa}$ \\
& Non-hardened carbon steel AISI & $58 \times 18 \times 5 \mathrm{~mm}$ & $3.3 \mathrm{GPa}$ \\
& 1045 & $\varnothing 16 \times 17 \mathrm{~mm}$ Radius $R$ of curvature $195 \mathrm{~mm}$ & $8.8 \mathrm{GPa}$ \\
Pin & Ball bearing steel AISI 52100 & $\varnothing 000 \mathrm{~mm}^{3}$ & $5.5 \times 10^{-3} \mathrm{~Pa} \mathrm{~s}\left(\right.$ at $\left.90^{\circ} \mathrm{C}\right)$ \\
\hline
\end{tabular}

Table 2

The preconditioning methods of the plates $(\mathrm{G}=$ ground, $\mathrm{S}=$ stress relieved, $\mathrm{N}=$ normalised, $\mathrm{Q}=$ quenched, $\mathrm{T}=$ tempered, $\mathrm{P}=$ polished; $\perp=$ perpendicular lines, $\|=$ longitudinal lines, \#=cross-hatched line pattern).

\begin{tabular}{|c|c|c|c|c|c|c|c|c|c|c|}
\hline \multirow[t]{2}{*}{ Group } & \multirow[t]{2}{*}{ Treatment } & \multirow[t]{2}{*}{ Laser power (kW) } & \multirow[t]{2}{*}{ Scan speed (mm s $\left.{ }^{1}\right)$} & \multirow[t]{2}{*}{$\beta$} & \multicolumn{6}{|c|}{ Preconditioning method } \\
\hline & & & & & $\mathbf{G}$ & $\mathbf{S}$ & $\mathbf{N}$ & $\mathbf{Q} \& \mathbf{T}$ & G & $\mathbf{P}$ \\
\hline 0 & Lines $\perp$ & 0.1 & 4.0 & $<0.5$ & & & $x$ & & $x$ & $x$ \\
\hline$\oplus$ & Lines $\perp$ & 0.1 & 4.0 & $>0.5$ & & & $x$ & & $x$ & $x$ \\
\hline$\odot$ & Lines $\|$ & 0.1 & 4.0 & $>0.5$ & & & $x$ & & $x$ & $x$ \\
\hline$\square$ & Lines \# & 0.1 & 4.0 & $>0.5$ & & & $x$ & & $x$ & $x$ \\
\hline$\square$ & Lines $\perp$ & 0.1 & 4.0 & $<0.5$ & & & $x$ & & $x$ & \\
\hline 田 & Lines $\perp$ & 0.1 & 4.0 & $>0.5$ & & & $x$ & & $x$ & \\
\hline$\bullet$ & Lines $\perp$ (molten) & 0.1 & 4.0 & $<0.5$ & & & $x$ & & $x$ & $x$ \\
\hline$\bullet$ & Lines $\perp$ (molten) & 0.1 & 4.0 & $>0.5$ & & & $x$ & & $x$ & $x$ \\
\hline 由 & Lines $\perp$ (molten) & 0.1 & 4.0 & $>0.5$ & & & $x$ & & $x$ & \\
\hline$\nabla$ & Line \| & 1.8 & 3.0 & 1.0 & $x$ & & & & & \\
\hline$\nabla$ & Line $\|$ & 1.8 & 6.0 & 1.0 & $x$ & & & & & \\
\hline$\nabla$ & Line $\|$ & 1.8 & 12.0 & 1.0 & $x$ & & & & & \\
\hline$\Delta$ & Line $\|$ & 1.8 & 3.0 & 1.0 & $x$ & $x$ & & & & \\
\hline$\Delta$ & Line $\|$ & 1.8 & 6.0 & 1.0 & $x$ & $x$ & & & & \\
\hline$\Delta$ & Line $\|$ & 1.8 & 12.0 & 1.0 & $x$ & $x$ & & & & \\
\hline$\diamond$ & Line $\|$ & 1.8 & 3.0 & 1.0 & $x$ & & $x$ & & & \\
\hline$\oplus$ & Line $\|$ & 1.8 & 6.0 & 1.0 & $x$ & & $x$ & & & \\
\hline$\odot$ & Line $\|$ & 1.8 & 12.0 & 1.0 & $x$ & & $x$ & & & \\
\hline 0 & Line $\|$ & 1.8 & 3.0 & 1.0 & $x$ & & & $x$ & & \\
\hline$\oplus$ & Line $\|$ & 1.8 & 6.0 & 1.0 & $x$ & & & $x$ & & \\
\hline$\odot$ & Line $\|$ & 1.8 & 12.0 & 1.0 & $x$ & & & $x$ & & \\
\hline+ & Linc $\|$ (no lubc) & 1.8 & 12.0 & 1.0 & $x$ & & & $x$ & & \\
\hline$\varnothing$ & Carburised & & & & $x$ & & & & & $x$ \\
\hline$*$ & Non-hardened & & & & $x$ & & & & & $x$ \\
\hline$x$ & Non-hardened & & & & $x$ & & & & & \\
\hline
\end{tabular}

Table 3

Different preheat treatments of the plates (vacuum $\approx 5 \times 10^{-5}$ Torr)

\begin{tabular}{|c|c|c|}
\hline Stress relieving & Normalising & Quenching + tempering \\
\hline $\begin{array}{l}\text { Heating up to } 650{ }^{\circ} \mathrm{C} \text { at a rate of } 30^{\circ} \mathrm{C} \\
\min ^{-1} \text { in furnace vacuum. Maintaining } \\
\text { the steel at } 6500^{\circ} \mathrm{C} \text { for } 18 \mathrm{~min} \text {. Cooling } \\
\text { down to room temperature at a rate of } \\
<20^{\circ} \mathrm{C} \text { in furnace. }\end{array}$ & $\begin{array}{l}\text { Heating up to } 850^{\circ} \mathrm{C} \text { at a rate of } 30^{\circ} \mathrm{C} \\
\min ^{-1} \text { in furnace vacuum. Maintaining } \\
\text { the steel at } 850^{\circ} \mathrm{C} \text { for } 18 \text { min. Cooling } \\
\text { down to room temperature at a rate of } \\
<20^{\circ} \mathrm{C} \text { in furnace. }\end{array}$ & $\begin{array}{l}\text { Heating up to } 850{ }^{\circ} \mathrm{C} \text { at a rate of } 30{ }^{\circ} \mathrm{C} \min ^{-1} \text { in } \\
\text { furnace vacuum. Maintaining the steel at } 850^{\circ} \mathrm{C} \text { for } \\
30 \text { min. Quenching the steel in water. Heating up to } \\
600{ }^{\circ} \mathrm{C} \text { at a rate of } 30^{\circ} \mathrm{C} \text { min }^{-1} \text { in furnace vacuum. } \\
\text { Maintaining the steel at } 600^{\circ} \mathrm{C} \text { for } 18 \text { min in fur- } \\
\text { nace vacuum. Cooling down to room temperature at } \\
\text { a rate of }<20^{\circ} \mathrm{C} \text { in furnace. }\end{array}$ \\
\hline
\end{tabular}

to the lines (see Fig. 2 for the directions). Hardness profiles of cross sections of some of the lines were measured too.
The plates hardened by the $0.1 \mathrm{~kW}$ laser beam have been provided with a line pattern perpendicular to the sliding direction of the pin (with respect to the plates). 


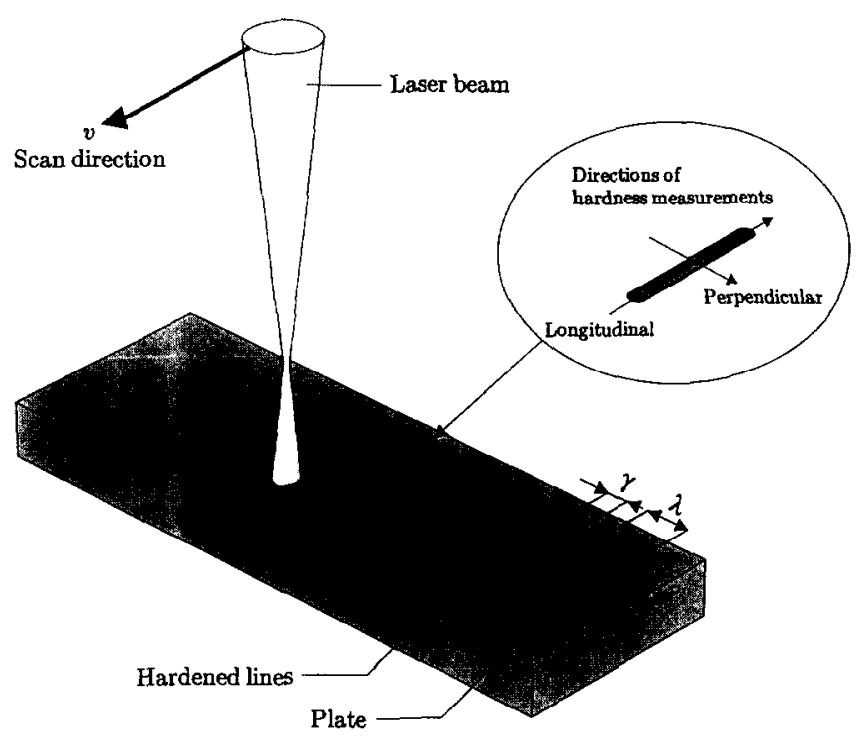

Fig. 2. Method of line hardening of the plate $\left(v=4 \mathrm{~mm} \mathrm{~s}^{-1}\right)$

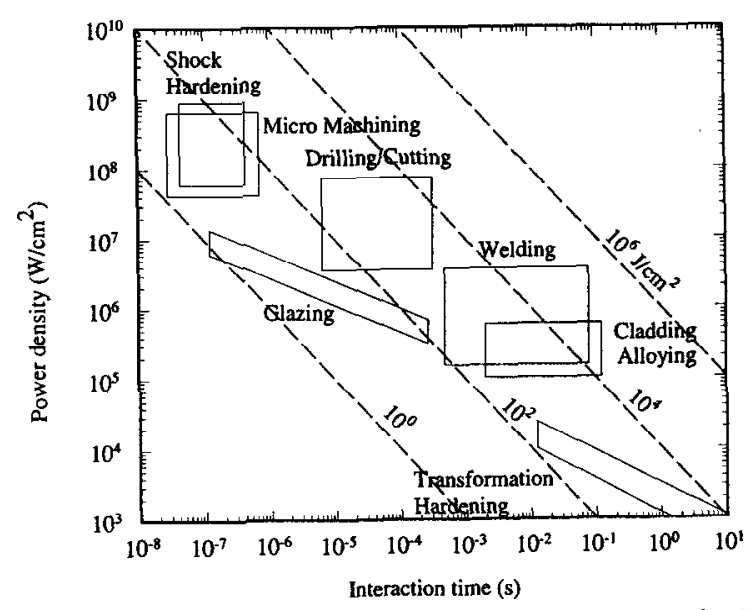

Fig. 3. Some surface treatment methods by laser, categorised after power density and interaction time (source: [7]).

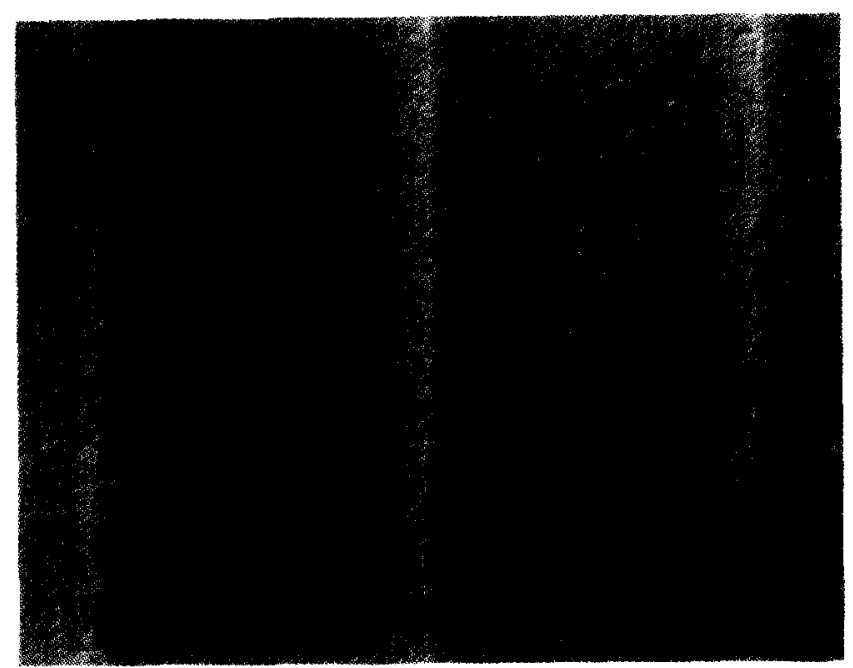

Fig. 4. Optical microscope photograph of line hardened plates (normalised, ground and polished; original magnification $=50 \times$ ).

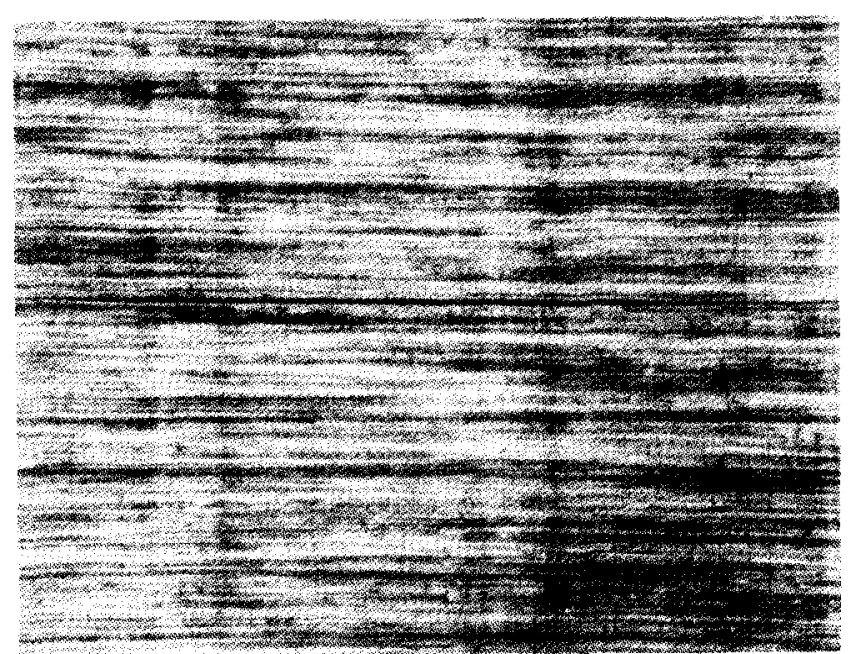

Fig. 5. Optical microscope photograph of line hardened plates (normalised and ground, original magnification $=50 \times$ ).

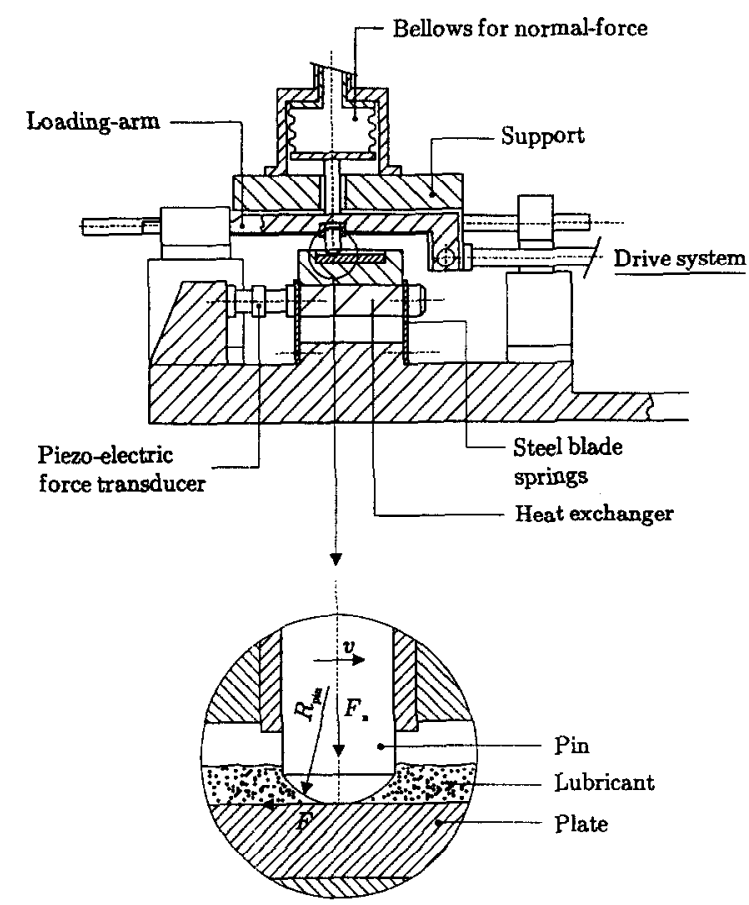

Fig. 6. Schematics of the reciprocating tribometer.

Two plates have been provided with cross-hatched $\left(45^{\circ}\right)$ line patterns or with lines parallel to the sliding direction of the pin. The pitch $\lambda$ and the line width $\gamma$ of the hardened lines were measured with an optical microscope as well as with a stylus profilometer.

The plates hardened by the $1.8 \mathrm{~kW}$ laser beam were provided with a single hardened line parallel to the sliding direction.

\subsection{Wear tests}

The wear tests were carried out on a reciprocating tribometer, as described by Vroegop and Bosma [8]. This tribometer is shown in Fig. 6 and consists basically 
of three parts: the plate holder, the pin holder and the driving system. The driving system produces a sinusoidal movement between pin and plate (the stroke is $48 \mathrm{~mm}$ ). The temperature of the plate is thermostatically controlled. The operational parameters (normal load, sliding speed (frequency), temperature, sliding distance) and tribological variables (friction force and wear depth) are continuously recorded by a process computer.

Prior to each wear test the plate and pin have been cleaned with ethanol in an ultrasonic bath and dried in hot air. The properties of the samples are given in Table 1 and the test conditions are given in Table 4.

The plate and pin were lubricated by a mineral paraffin oil with a viscosity of $5.5 \mathrm{mPa}$ s at a temperature of $90^{\circ} \mathrm{C}$. The wear tests were performed under constant load $(500 \mathrm{~N})$. The temperature of the elements and frequency of the motion have been chosen such that during the wear process the system operated in the boundary lubrication regime. In this regime the friction is independent of the sliding velocity. Therefore friction was measured continuously at the centre of the stroke (where the sliding velocity is highest) and at both ends of the stroke (where the sliding velocity equals zero). In case of a line pattern perpendicular to the sliding direction the pitch $\lambda$ and the width $\gamma$ of the hardened lines (see Fig. 2) were chosen such that at least two lines in the nominal contact area were in contact with the pin. In this way it was assured that the applied load was carried by the hardened lines. The nominal contact pressure in the boundary lubricated contact area was about $1 \mathrm{GPa}$, and the sliding velocities were 15 and $60 \mathrm{~mm} \mathrm{~s}^{-1}$. The coefficient of friction was approximately 0.1 which makes the generated energy density in the contact during sliding well below $10^{2} \mathrm{~W}$ $\mathrm{cm}^{-2}$.

The samples were weighed with a precision balance to an accuracy of $0.01 \mathrm{mg}$. After each wear test the samples were cleaned and weighed again. From the weight loss of the samples a wear volume $\Delta V$ was calculated. To supplement weight loss measurements, profile traces were taken perpendicular to the wear track of the plate by means of a stylus profilometer. The geometry of the wear track at the plate (track width, length and wear depth $D_{\text {plate }}$ ) and the circular contact area of the pin (that is, the radius and the wear depth $D_{\text {pin }}$ ) have been measured by means of an

Table 4

Experimental conditions

\begin{tabular}{ll}
\hline Applied normal load & $500 \mathrm{~N}$, constant \\
Amplitude of sinusoidal velocity & $15.1-60.3 \mathrm{~mm} \mathrm{~s}$ \\
Temperature of the plate & $90^{\circ} \mathrm{C}$, constant \\
Sliding distance & $600-3000 \mathrm{~m}$
\end{tabular}

optical microscope and a stylus profilometer. Using these geometrical data the wear volumes $\Delta V$ of plate and pin have been calculated and compared with the values obtained by the weight loss method. From the wear volume of the samples, the specific wear rates, $k_{\text {pin }}$ and $k_{\text {plate }}$ were calculated using,

$k=\frac{\Delta V}{F_{\mathrm{n}} s}$

in which $k$ is the specific wear rate of the sample (pin or plate, $\left.\mathrm{mm}^{3} \mathrm{~N}^{-1} \mathrm{~m}^{-1}\right), F_{\mathrm{n}}$ the applied normal load $(\mathrm{N}), s$ the sliding distance $(\mathrm{m})$, and $\Delta V$ the volume loss of the sample (pin or plate, $\mathrm{mm}^{3}$ ).

\section{Results and discussion}

The wear depth of the line hardened surface is much lower then the hardening depth. Therefore it is permitted to attribute changes in wear rate to the presence of the hardened lines. The wear rates of plate and pin can be conveniently arranged by plotting each wear rate $k_{\text {plate }}$ of the plate against its corresponding wear rate $k_{\text {pin }}$ of the pin. In this way a graph is obtained which gives the wear behaviour of the different tribological systems. These graphs are meaningful when the wear rate of each system is constant during the wear process.

\subsection{Wear rates vs. sliding distance}

If the wear depth $D_{\text {plate }}$ of the plate and the elastic deformation of plate and pin are negligible, with respect to the wear depth $D_{\text {pin }}$ of the pin then the following relation can be derived between the measured wear depth $D$ and the sliding distance $s$ of a plate-sphere geometry (see Appendix),

$D_{\text {pin }} \approx \mathrm{a}+\mathrm{b} \sqrt{s}$

in which $a$ and $b$ are constants. Fig. 7 shows the recorded wear depth $D$ as a function of the square root of the sliding distance $s$. The constants $\mathrm{a}$ and $\mathrm{b}$ have been calculated from the measured $D(\sqrt{s})$ values by means of a least square method. The constant $b$ gives an indication of the wear rate of the pin,

$k_{\mathrm{pin}}=\frac{\pi \mathrm{b}^{2} R_{\mathrm{pin}}}{F_{\mathrm{n}}}$

in which $R_{\mathrm{pin}}$ is the original radius of curvature of the pin. From the calculated correlation coefficients between the sliding distance $\sqrt{s}$ and the depth $D$ (about 0.97) it can be concluded that the wear rate was reasonably constant after a sliding distance of about $100 \mathrm{~m}$. 


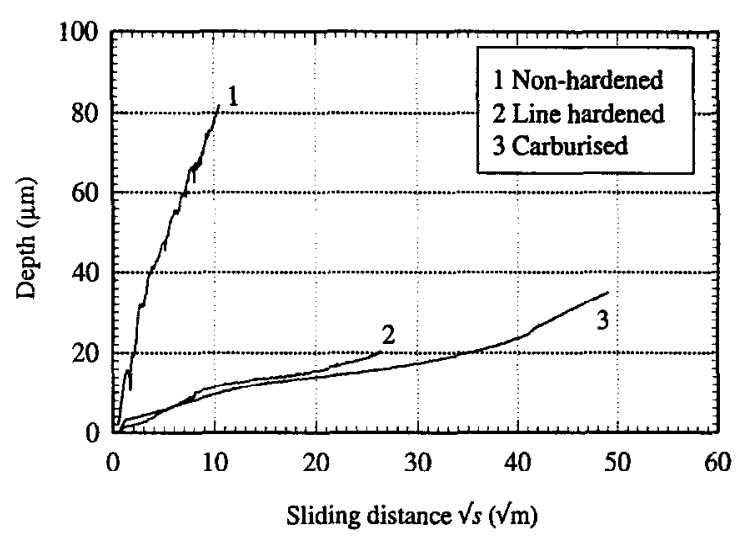

Fig. 7. Recorded wear depth, $D$, as a function of the square root of the sliding distance, $s$.

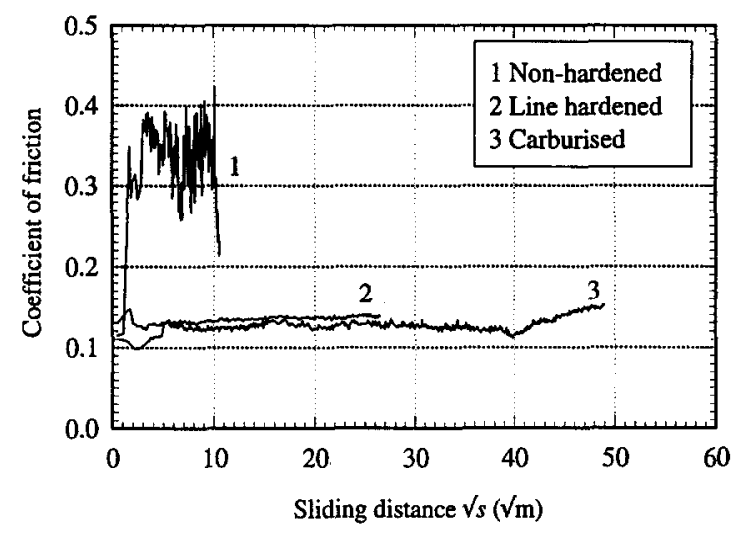

Fig. 8. Recorded coefficient of friction as a function of the square root of the sliding distance, $s$.

\subsection{Wear rates of line hardened, carburised and non- hardened steel 1045}

When a non-hardened plate of steel AIS1 1045 slid against a pin of steel AISI 52100 mainly severe adhesive wear appeared at the plate. Material was transferred from the plate to the pin. Because of this transfer the weight loss of the pin was negative. The wear rate of the plate was in the order of $10^{-4} \mathrm{~mm}^{3} \mathrm{~N}^{-1} \mathrm{~m}^{-1}$ in magnitude. During the wear process, the scattering in friction between plate and pin was very high (see Fig. 8).

Wear tests with carburised and line hardened plates of steel AISI 1045 against a pin of steel AISI 52100 gave primarily a mixture of mild oxidative and microabrasive wear. The scattering in friction was less than that of the non-hardened plates (see Fig. 8). The wear rate of the hardened plates as well as that of the pins was in the order of $10^{-7} \mathrm{~mm}^{3} \mathrm{~N}^{-1} \mathrm{~m}^{-1}$ in magnitude. With regard to the non-hardened plates the wear resistance improved as a result of line hardening and carburising the plates (see Fig. 9).

With line hardened plates of steel AISI 1045 the wear resistance of the pins decreased. This shows that

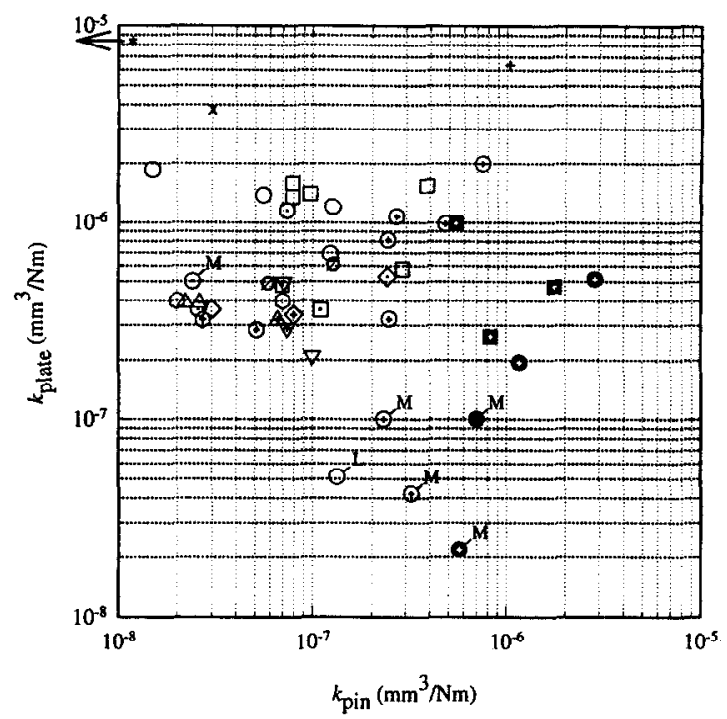

Fig. 9. Wear rates of plate and pin according to the type of plates ( $M=$ Mejjer et al., 1985; other points are from this study; $L=$ wear test in which some mixed lubrication occurred. The symbols are defined in Table 2).

only line hardening the plates does not improve the entire tribological system.

\subsection{Wear rate vs. preheat treatments}

Fig. 9 shows the wear rate of plate and pin according to the preconditioning methods applied prior to line hardening. The ground and polished plates were all hardened by the $0.1 \mathrm{~kW}$ laser. The other plates where hardened by the $1.8 \mathrm{~kW}$ laser. It can be seen that the wear rate is not affected by the type of heat treatment applied.

\subsection{Wear rate vs. interaction time}

In order to study the effect of interaction time between laser beam and the plate surface the plates hardened by the $1.8 \mathrm{~kW}$ laser, have been hardened with different speeds $\left(3,6\right.$ and $12 \mathrm{~mm} \mathrm{~s}^{-1}$, corresponding to interaction times of $0.5,1.0$ and $2.0 \mathrm{~s}$ respectively). In Fig. 9 the wear rates of plate and pin are given according to the interaction time. It follows that the wear rates of plate and pin are not significantly affected by the interaction time.

\subsection{Wear rate vs. molten lines}

When the power of the laser beam exceeds a certain limit the material in the centre of the spot starts to melt. After self-quenching of such areas sharp peaks appear at the edges of the lines. Figs. 10 and 11 show clearly, that the topography has changed drastically as a result of the melting process. 


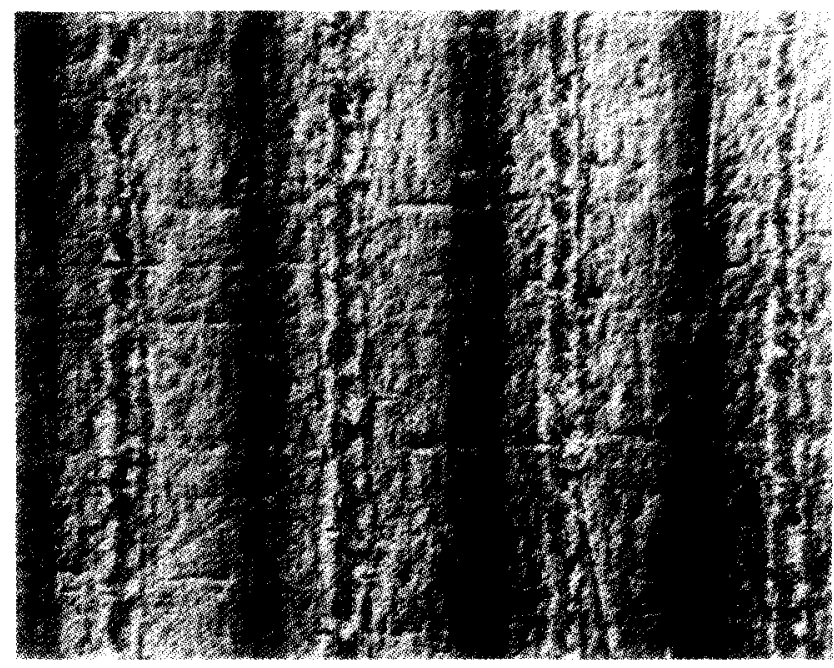

Fig. 10. Optical microscope photograph of molten lines (magnification $=50 \times$ ).

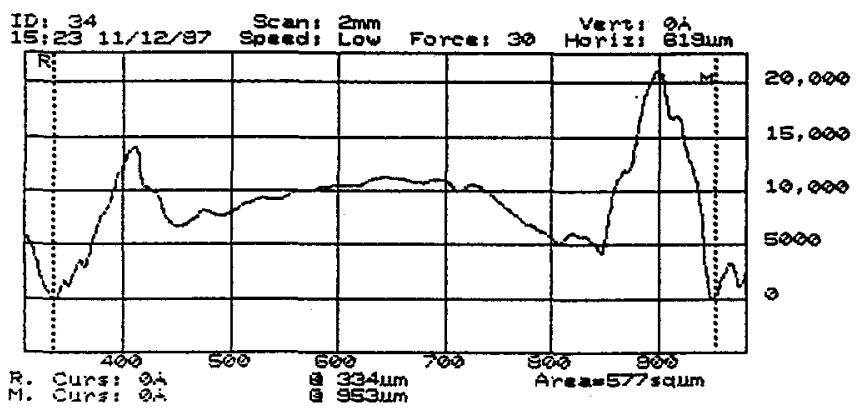

Fig. 11. Surface profile of lines which have been molten during the laser treatment.

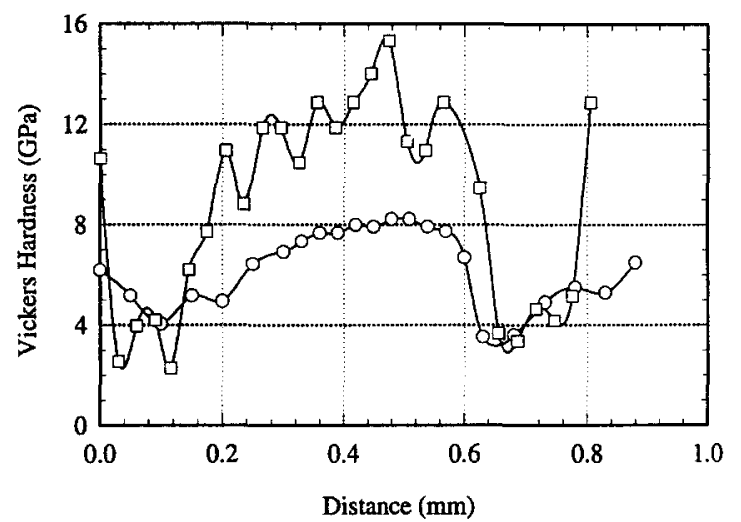

Fig. 12. Hardness profiles at the surface of a line which have been molten $\left(O\right.$, load $=2 \mathrm{~N}, \square$, load $=250 \mathrm{mN}, H_{\mathrm{v}}=1 \mathrm{kgf} \mathrm{mm}^{-2}=10^{-2}$ $\mathrm{GPa}$ ).

Besides these topographical features the hardened lines may possess a thin hard layer in the middle. At high indentation loads $(2 \mathrm{~N})$ the Vickers microhardness was about $8.4 \mathrm{GPa}$ (a normal value for hardened lines, see Fig. 12). At a low indentation load $(250 \mathrm{mN})$ the hardness was much higher (about $12.0 \mathrm{GPa}$ ) and showed much scatter. This indicates that a thin hard layer exists in the areas that have been molten. From an X-ray diffraction pattern it followed that no cementite was present in the thin layer. Furthermore, the diffraction angles of the $\gamma$-phase (austenite) were much greater than would have been expected. This may have been caused by a deformation of the crystal lattice due to a high concentration of carbon in the thin layer as a result of retained austenite. An electron probe micro analysis (EPMA) was carried out to investigate the carbon concentration in a hardened line molten during the laser treatment. The carbon concentration was measured in a cross section of the line from the surface downwards to a depth of about $200 \mu \mathrm{m}$. The radius of the electron beam was $0.5 \mu \mathrm{m}$. At this scale the distribution of carbon is inhomogeneous. Therefore the concentration was line-averaged as shown in Fig. 13 which gives the measured carbon concentration as a function of case depth for a molten line. In a cross section of a molten line the carbon concentration rises sharply within a thickness of $20 \mu \mathrm{m}$ near the surface. No increase in carbon concentration was found in a cross section of a normal hardened line. Hence, it may be concluded that the dendritic grey layer and the white etching layer on top of the martensitic area as proposed by [1] is not in conflict with above mentioned results.

Fig. 14 shows the wear rates of plate and pin. A distinction is made between plates with normal lines and plates with molten lines. The wear resistance of the pin is considerably lower as a result of molten lines. It is clear that the higher wear rates of the pin are due to the hard thin layer on top of the martensitic area.

\subsection{Coverage vs. wear rate}

In case of hardening the plates by the $0.1 \mathrm{~kW}$ laser beam, the pitch $\lambda$ of the hardened lines was varied

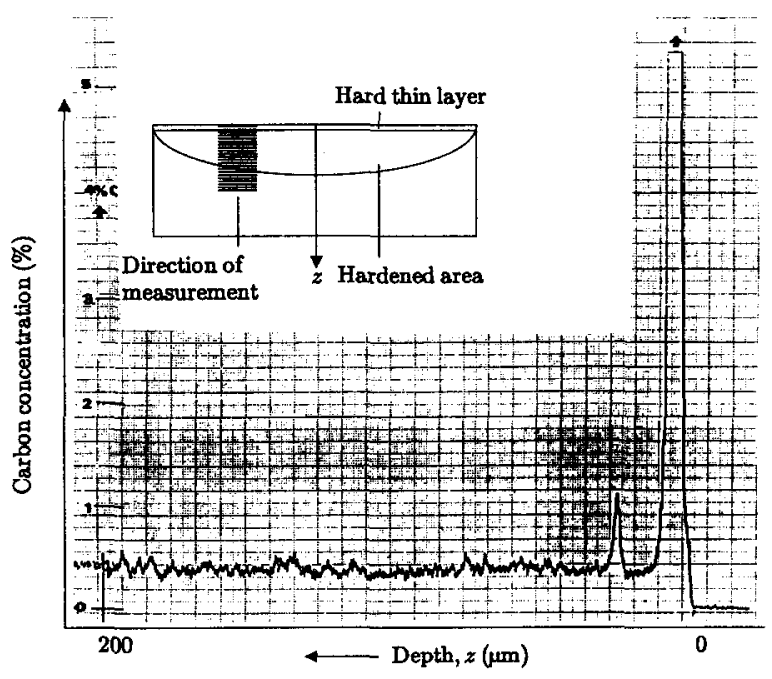

Fig. 13. Measured carbon concentration at a molten line as a function of case depth. 


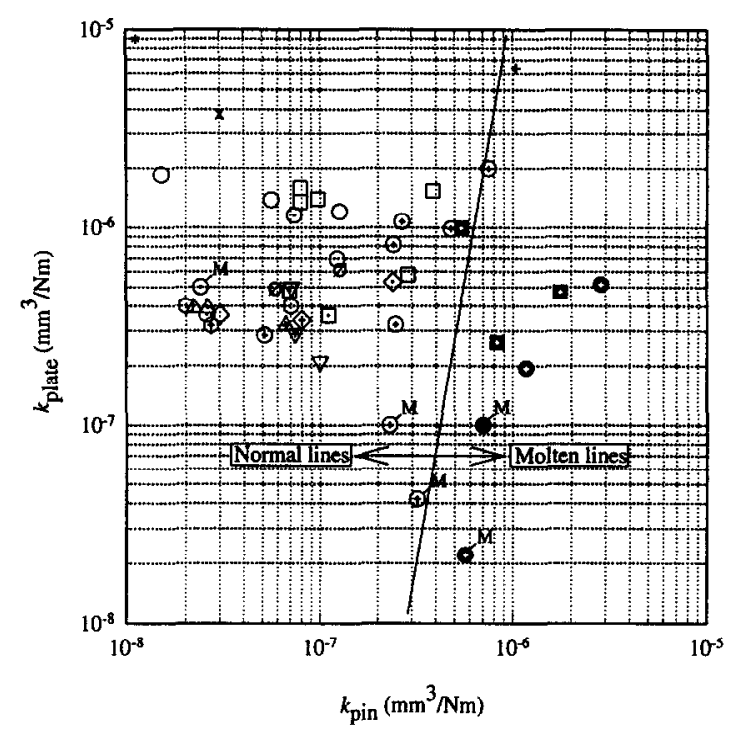

Fig. 14. Wear rate of plate and pin according to normal (open symbols) and molten (filled symbols) lines (the symbols are defined in Table 2).

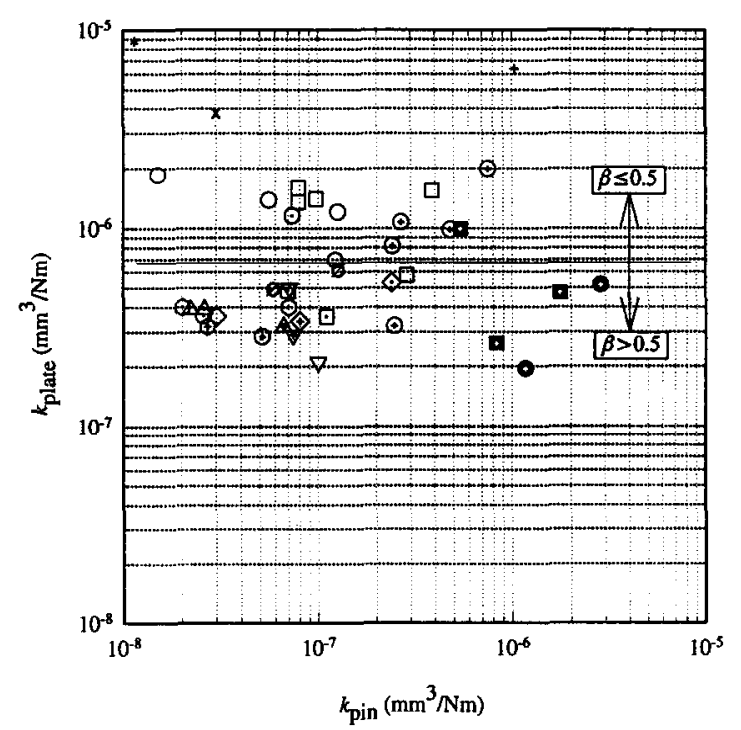

Fig. 15. Wear rate of plate and pin according to coverage ratio, $\beta$ (the symbols are defined in Table 2).

from $600-900 \mu \mathrm{m}$. The width $\gamma$ was changed (by defocussing the laser beam) from $120-600 \mu \mathrm{m}$. As a result the coverage ratio $\beta$ (i.e. $\gamma / \lambda$ ) varied between 0.13 and 1.0. To eliminate melting of the lines the power density was reduced by $50 \%$.

Fig. 15 shows the wear rate of plate and pin according to coverage ratio $\beta$. At line hardened plates with low coverage ratio basically adhesive wear appeared, although not in such an amount as with non-hardened plates. The load was partly carried by the hardened lines and partly by the softer base material. Pits appeared in the wear track close to the hardened lines (see Fig. 16). At these pits material was removed by and smeared onto the pin. As a result of the lower coverage ratio the wear mechanism changed from oxidative and ab-

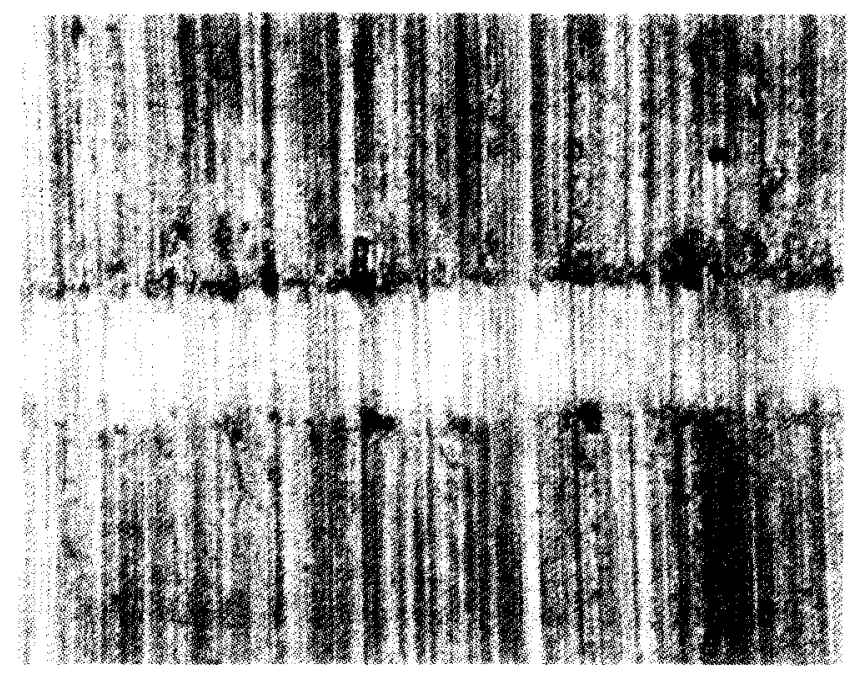

Fig. 16. Wear track of a plate with a coverage ratio, $\beta$, of 0.2 (magnification $=100 \times$ ).

rasive wear to adhesive wear and the wear rate of the plate increased. The wear rate of the pin did not change significantly.

\subsection{Wear rate vs. line pattern}

As can be seen from Fig. 9 the tests with a line pattern parallel to the direction of motion of the pin did not yield wear rates much different from that of a line pattern perpendicular to the direction of motion. Cross-hatched patterns showed a slightly better wear resistance compared to parallel or perpendicular line patterns. This is in agreement with the expectations as long as the loaded contact is carried by the hardened lines.

\subsection{Roughness vs. wear rate}

From Fig. 9 it follows that no significant differences in the wear rate of plate and pin can be found between plates with different roughnesses (the roughness measured before line hardening). The reason for this is that during these wear tests after a running-in period of approximately $100 \mathrm{~m}$ a process-roughness develops, which is different from the initial roughness prior to the wear test.

\section{Conclusions}

- The wear resistance of steel AISI 1045 (normal trade quality) against steel AISI 52100 can considerably be improved by line hardening the surface. This investigation showed that the wear resistance of a laser line hardened surface is at least comparable to that of a conventional hardened (carburised) surface. The advantage of laser hardening 
is that hardening can be restricted to local areas which are subjected to wear.

- The type of heat treatment (stress relieving, normalising or quenching + tempering) carried out prior to the laser line hardening of the steel has no significant influence on the wear behaviour of the tribological system.

- Changing the interaction time from 0.5-2 s has no effect on the wear rate of the system.

- A roughness refinement of the line hardened surface from $0.1-0.01 \mu \mathrm{m}$ CLA-roughness - by means of a polishing treatment prior to the laser heat treatment-has no significant effect on the wear resistance of the tribological system. Hence, such a refinement is not necessary in order to improve the wear resistance.

- When, during the laser heat treatment, the surface temperature exceeds the melting point of the material (due to a high power density and/or low scan speed) then the hardened lines obtain a thin hard layer after self-quenching. The microhardness in this layer can be very high. When such surfaces are applied in a tribological system, the wear resistance of the opposite surface deteriorates drastically.

- Surfaces containing hardened lines parallel to the sliding direction did not show much difference in wear resistance from those containing lines perpendicular to the sliding direction.

- The wear resistance of a line hardened surface decreases with decreasing coverage ratio showing a change in wear mechanism from mixed oxidation and abrasive wear to adhesive wear. The wear resistance of the surface is higher when the lines are harder.

- In general, the wear resistance of a tribological system is not improved by line hardening one surface only.

\section{Acknowledgements}

The authors wish to thank Mr. G.J.W. Wes for hardening the samples and Dr. J. Meijer and Mr. P.F. Willemse for their contribution to the discussion of the results described in this paper.

\section{Appendix A: Derivation of Eqs. (2) and (3)}

It will be assumed that the worn area of the pin is flat and circular with a contact radius of $r$, as the inset of Fig. 1 shows. When the radius of the pin, $R_{\text {pin }} \gg r$, then the wear depth, $D_{\text {pin }}$, of the pin can be approximated by a parabolic function,
$D_{\text {pin }}=\frac{r^{2}}{2 R_{\text {pin }}}$

After a sliding distance, $\mathrm{d} s$, the pin has worn,

$\mathrm{d} V_{\text {pin }}=\pi r^{2} \mathrm{~d} D_{\text {pin }}=2 \pi R_{\text {pin }} D_{\text {pin }} \mathrm{d} D_{\text {pin }}$

The increase in specific wear rate of the pin after this sliding distance is,

$\mathrm{d} k_{\text {pin }}=\frac{1}{F_{\mathrm{n}}} \frac{\mathrm{d} V_{\mathrm{pin}}}{\mathrm{d} s}=2 \pi R_{\mathrm{pin}} D_{\mathrm{pin}} \frac{1}{F_{\mathrm{n}}} \frac{\mathrm{d} D_{\mathrm{pin}}}{\mathrm{d} s}$

Integration of (6) gives the mean specific wear rate, $k_{\mathrm{pin}}$, of the pin after a sliding distance, $s$, (when $F_{\mathrm{n}}$ is constant),

$k_{\mathrm{pin}}=\frac{1}{s} \int_{s} \mathrm{~d} k_{\mathrm{pin}} \mathrm{d} s=\frac{\pi R_{\mathrm{pin}}}{F_{\mathrm{n}} s}\left(D_{\mathrm{pin}}^{2}(s)-D_{\mathrm{pin}}^{2}\left(s_{0}\right)\right)$

in which $s_{0}$ is the sliding distance at the beginning of the depth measurement. The measured wear depth, $D(s)$ is in general a function of the wear depths of the plate and the pin, $D_{\text {plate }}$ and $D_{\text {pin }}$, the elastic deformation, $D_{\mathrm{e}}$ of the plate and pin and a displacement, $D_{\mathrm{T}}$ as a result of temperature changes,

$D(s)=D_{\text {plate }}(s)+D_{\text {pin }}(s)+D_{e}(s)+D_{\mathbf{T}}(s)$

The hardness of the line hardened plates and the pins are of the same order. Furthermore, the total wear track area of the plate is much larger than the contact area of the pin. Consequently, the wear depth of the plate is much smaller than that of the pin, i.e $D_{\text {plate }} \ll D_{\text {pin }}$. If $D_{\text {plate }} \ll D_{\mathrm{e}}$ and the temperature is constant, i.e. $D_{\mathrm{T}}=0$, then the wear depth of the pin follows from (8),

$D_{\text {pin }}(s)=D(s)-D_{e}(s)$

Substitution of (9) into (7) gives,

$k_{\mathrm{pin}}=\frac{\pi R_{\mathrm{pin}}}{F_{\mathrm{n}} s}\left(\left(D(s)-D_{\mathrm{e}}(s)\right)^{2}-\left(D\left(s_{0}\right)-D_{\mathrm{c}}\left(s_{0}\right)\right)^{2}\right)$

At $s=s_{0}$ the pin has not worn yet, therefore $D_{\mathrm{pin}}=0$ and from (9) it follows that $D\left(s_{0}\right)=D_{\mathrm{e}}\left(s_{0}\right)$. Then the wear rate of the pin becomes,

$k_{\mathrm{pin}}=\frac{\pi R_{\mathrm{pin}}}{F_{\mathrm{n}} s}\left(D(s)-D_{\mathrm{e}}(s)\right)^{2}$

As the wear volume of the pin increases with sliding distance, the contribution of the elastic deformation $D_{\mathrm{e}}$ on the measured displacement $D$ will become less and after a certain sliding distance it will become negligible. The measured wear depth, $D$, can then be written as $(s>0)$,

$D(s)=\mathrm{a}+\mathrm{b} \sqrt{s}$

in which 
$\mathrm{a}=D_{\mathrm{e}}$

and

$\mathrm{b}=\sqrt{\frac{k_{\mathrm{pin}} F_{\mathrm{n}}}{\pi R_{\mathrm{pin}}}}$

If the specific wear rate, $k_{\text {pin }}$, of the pin is constant then it follows from (14) that,

$k_{\mathrm{pin}}=\frac{\pi \mathrm{b}^{2} R_{\mathrm{pin}}}{F_{\mathrm{n}}}$

\section{References}

[1] J. Meijer, M. Seegers, P.H. Vroegop and G.J. Wes, Line hardening by low-power $\mathrm{CO}_{2}$-lasers, in $\mathrm{C}$. Albright (ed.), Proc. Int. Conf. on Application of Lasers and Electro-optics (ICALEO),
San Francisco, 1985, The Laser Institute of America, Toledo, OH, 1986, pp. 229-238.

[2] O.A. Gorlenko, V.P. Tikhomirov and E.N. Frolov, Quality and wear strength of machined surfaces after laser processing, $4^{\text {th }}$ Europ. Tribol. Congr., Eurotrib 1985, Elsevier, Amsterdam, Vol. 3, Section 1.4, pp. 1-2.

[3] M. Kikuchi, H. Hisada, Y. Kuroda and K. Moritsu, The influence of laser heat treatment technique on mechanical properties, in Proc. First Joint U.S.JJapan Int. Laser Proc. Conf., Anaheim, CA, 1981, Laser Institute of America, Toledo, Ohio, 1981, Paper No. 12.

[4] H.B. Singh, S.M. Copley and M. Bass, Fatigue resistance of laser heat treated 1045 carbon steel, Metall. Trans., $12 \mathrm{~A}$ (1) (1981) 138-140.

[5] A.G. Grigor'yants, A.N. Safonov, V.M. Tarasenko, N.Yu. Mareev, Structure and hardness of steel $\mathrm{C} 45$ after irradiation with a $\mathrm{CO}_{2}$ laser, Met. Sci. Heat Treat., 24 (9) (1982) 629-632.

[6] C.M. Preece and C.W. Draper, The effect of laser quenching the surfaces of steels on their cavitation erosion resistance, Wear, 67 (1981) 321-328.

[7] Laserbewerkingen, FME, Vereniging voor de metaal- en de elektrotechnische industrie, 1988, p. 21 (in Dutch).

[8] P.H. Vroegop and R. Bosma, Subsurface melting of nylon by friction-induced vibrations, Wear, 104 (1985) 31-47. 